\title{
AS CONTRIBUIÇÕES DOS ESTUDOS CONTEMPORÂNEOS PARA O PROCESSO DE TOMADA DE DECISÃO
}

The contributions of contemporary studies of emotions for decision-making process

Silvia Cenzollo Peloi *

Resumo: Este artigo tem como objetivo apresentar uma reflexão a respeito do estudo do processo decisório humano diante de recentes pesquisas que destacam o fator emocional como fundamental no processo de tomada de decisões. A exposição se inicia com um breve apanhado histórico, analisando as considerações de René Descartes e da ciência cognitiva a respeito do papel das emoções no processo decisório. Em seguida, apresenta as conclusões do neurocientista António Damásio a respeito do tema, bem como de outras pesquisas realizadas que concluíram pela importância da emoção no processo decisório. Em continuidade, serão expostos argumentos que apontam para a incapacidade humana de decidir unicamente com base no pilar fundamental da ética utilitária, o Princípio da Maior Felicidade.

Palavras-chave: Emoções, Utilitarismo, Tomada de decisão.

\begin{abstract}
This article aims to present a reflection about the study of the human decision-making process related to recent researches that highlight the emotional factor as fundamental for the decisionmaking. The content begins with a brief historical overview, analyzing René Descartes' considerations and the point of view of the cognitive science about the role of emotions in decision-making. Then, it presents the findings of neuroscientist António Damásio on the subject, as well as other conducted surveys that concluded about the importance of emotion for the decision-making process. Afterwards, we expose some arguments that point to the human inability to make a decision based only on the fundamental pillar of utilitarian ethics, the Greatest Happiness Principle.
\end{abstract}

Keywords: Emotions, Utilitarianism, Decision making.

* Mestranda em Filosofia pela PUC-PR - silvia_ccp@hotmail.com.

\begin{tabular}{|c|c|l|l|l|l|}
\hline intuitio & $\begin{array}{c}\text { ISSN } \\
1983-4012\end{array}$ & Porto Alegre & Vol.8 $-\mathrm{N}^{\circ} .1$ & $\begin{array}{c}\text { Junho } \\
2015\end{array}$ & p.104-122 \\
\hline
\end{tabular}


As contribuições dos estudos contemporâneos das emoções para o processo de tomada de decisão

\section{Introdução}

O que motiva os seres humanos a agir dentro dos padrões que consideramos morais: a razão ou a emoção? Como os filósofos têm respondido a esta indagação ao longo do tempo? É com o objetivo de tecer algumas considerações sobre perguntas como estas que este estudo se apresenta. O presente artigo irá analisar, a partir de uma perspectiva filosófica, o papel atribuído às emoções no processo de tomada de decisão, sobretudo decisões morais, tendo como base teórica as questões filosóficas dos estudos do neurocientista português António Damásio. Este tema apresenta grande relevância na atualidade. Não que os motivos das decisões morais não tenham sido objeto de estudos filosóficos, ao contrário, filósofos de todos os tempos envidaram esforços para compreender o tema em questão. Hoje, no entanto, o debate ganha uma nova perspectiva devido ao avanço científico no estudo do cérebro humano. A partir do desenvolvimento de modernas tecnologias de neuroimagem, atualmente é possível analisar o cérebro no momento em que determinada atividade é realizada. Como explica João de Fernandes Teixeira na obra Filosofia do Cérebro, as técnicas de neuroimagem surgiram em meados da década de 1990. Antes, a única maneira de examinar o cérebro humano era por meio de autópsias. Devido às limitações de uma análise dessa natureza, muito pouco se sabia a respeito da atividade cerebral ${ }^{1}$. Com o desenvolvimento das tecnologias de imageamento houve uma mudança drástica a respeito do conhecimento do funcionamento do cérebro. As técnicas do PET e do fMRI proporcionaram, pela primeira vez, visualizar o cérebro vivo em atividade ${ }^{2}$.

As conclusões dos estudos realizados com base em tais tecnologias provocaram grande impacto em questões filosóficas tradicionais. Muitos filósofos começaram a se utilizar de tais conclusões para a formulação de teorias a respeito da mente, da consciência e do processo decisório.

Este trabalho irá abordar, inicialmente, a forma como a filosofia, em especial a filosofia moderna, ocupou-se do tema, concluindo pela supremacia da razão no processo decisório. Considerando a necessidade de delimitação de um trabalho desta natureza, será objeto de análise, inicialmente, a filosofia de René Descartes, e o que o filósofo disse a respeito da razão, emoção e decisões. Em seguida será feita uma abordagem da ciência cognitiva. Será mostrado como, embora tenha representado um grande avanço no estudo da mente humana , a ciência cognitiva se manteve fiel à tradicional dicotomia entre razão e emoção. Em seguida, será apresentado o pensamento do neurocientista António Damásio. A partir de

${ }^{1}$ TEIXEIRA, J. F. de. Filosofia do cérebro. São Paulo: Paulus, 2012, p.11.

${ }^{2}$ Tais técnicas funcionam, basicamente, da seguinte maneira: o paciente (humano ou não) realiza alguma atividade cognitiva enquanto tem o cérebro escaneado. Eventos neurais requerem oxigênio; portanto, fluxo sanguíneo aporta para os locais em atividade. O exame permite verificar a área do cérebro na qual houve maior aporte de fluxo sanguíneo. Isso permite que a atividade seja localizada no tecido cerebral. Em tese, tais técnicas possibilitariam o mapeamento integral do cérebro - ou da mente nele - por meio da identificação de todas as áreas envolvidas em todas as atividades humanas.

\begin{tabular}{|c|c|c|c|c|c|}
\hline intuitio & $\begin{array}{c}\text { ISSN } \\
1983-4012\end{array}$ & Porto Alegre & Vol.8 $-\mathrm{N}^{\circ} .1$ & $\begin{array}{c}\text { Junho } \\
2015\end{array}$ & p.104-122 \\
\hline
\end{tabular}


As contribuições dos estudos contemporâneos das emoções para o processo de tomada de decisão

estudos com pacientes que apresentaram substancial mudança comportamental depois de sofrerem lesões no córtex pré-frontal, ele formulou uma teoria inovadora, denominada hipótese do marcador-somático, que coloca o fator emocional em papel de destaque no processo de tomada de decisões.

A relevância da obra de Damásio reside, entre outros aspectos, no estímulo que proporcionou à produção intelectual a respeito do tema. Muitos estudos foram desenvolvidos com o intuito de compreender a importância do fator emocional no processo decisório. Os resultados de tais estudos colocam em dúvida a possibilidade de aplicação prática, em determinadas situações, de uma das correntes filosóficas que mais influenciou o ocidente nos últimos séculos: o utilitarismo. Para compreender os motivos desta alegação, este artigo tratará das premissas da ética utilitarista, e também esclarecerá as razões pelas quais os resultados dos estudos a respeito das emoções colocam em dúvida a possibilidade de aplicação prática dos pressupostos que ela abarca.

Cumpre ressaltar, que embora o presente estudo apresente diversos dados neurocientíficos, a abordagem é eminentemente filosófica. Nisto reside o traço característico do presente trabalho: analisar, sob uma perspectiva filosófica, o papel das emoções no processo decisório.

\section{Fundamentação teórica}

\subsection{Razão e Emoção na filosofia de René Descartes}

A filosofia de René Descartes influenciou profundamente o pensamento ocidental , sobretudo na teoria que desenvolveu a respeito da dicotomia entre mente e corpo. Embora as ideias cartesianas tenham sofrido as mais variadas críticas, os problemas e soluções por ele abordados ainda são objeto de análise na filosofia atual. Para falar sobre a filosofia cartesiana a respeito de razão e emoção, é preciso tecer algumas considerações gerais sobre a filosofia de René Descartes, para que seja possível compreender sob quais fundamentos o filósofo construiu suas proposições.

Como esclarece Étienne Gilson ${ }^{3}$, Descartes constrói a própria filosofia a partir de uma concepção fundamental: a de que é possível encontrar um método universal, capaz de resolver todos os problemas que o espírito humano possa colocar. Se o espírito estiver acostumado às exigências do verdadeiro método, poderá transportá-lo para outros domínios, aplicando a mesma certeza matemática para todas as ciências. Embora esse empreendimento possa parecer um tanto ilusório - já que não seria possível reduzir tudo, incluindo a metafísica e a moral, ao cálculo - não é impossível tratar tais problemas matematicamente.

${ }^{3}$ DESCARTES, R. Discurso do Método. Introdução, análise e notas de Étienne Gilson. São Paulo: Martins Fontes, 2009, p. VIII.

\begin{tabular}{|c|c|c|c|c|c|}
\hline intuitio & $\begin{array}{c}\text { ISSN } \\
1983-4012\end{array}$ & Porto Alegre & Vol.8 $-\mathrm{N}^{\mathrm{o} .1}$ & $\begin{array}{c}\text { Junho } \\
2015\end{array}$ & p.104-122 \\
\hline
\end{tabular}


As contribuições dos estudos contemporâneos das emoções para o processo de tomada de decisão

Ademais, o cálculo é apenas um instrumento do qual a aritmética se serve. Não é necessário que o espírito se submeta ao cálculo; apenas que se utilize da certeza peculiar à matemática, a qual decorre da evidência perfeita das ideias que nela são empregadas. Como Descartes observa na obra Discurso do Método, não é possível encontrar essa certeza nas ideias já construídas, pois "enquanto me limitei a considerar os costumes dos outros homens, quase nada encontrei que me desse segurança, e notava quase tanta diversidade quanto antes observara entre as opiniões dos filósofos"

Diante da necessidade de construir o saber em fundamentos seguros, Descartes elencou quatro preceitos que considerou suficientes para fundar a própria filosofia. O primeiro, de "nunca aceitar coisa alguma como verdadeira sem que a conhecesse evidentemente como tal" conclusão precipitada. O segundo, dividir cada problema em quantas parcelas fossem possíveis, para melhor resolvê-lo. Terceiro, de conduzir o pensamento "pelos objetos mais simples e mais fáceis de conhecer, para subir pouco a pouco, como por degraus, até o conhecimento dos mais compostos" ${ }^{6}$. O último, enumerar sempre, da maneira mais complexa possível, com revisões muito gerais, para nada omitir.

Partindo dessas premissas Descartes examina os fundamentos do saber tradicional. Um destes fundamentos é a experiência sensível. Ainda na obra "Discurso do Método", analisando tal fundamento, conclui que a experiência sensível não pode ser fundamento do saber, pois nossos sentidos às vezes nos enganam. Outro possível fundamento seria o poder discursivo da razão ou o pensamento. Contudo, após analisar o tema, Descartes conclui que mesmo o pensamento pode nos enganar, pois não há garantias de que os pensamentos que nos ocorram sejam mais verdadeiros do que as ilusões que nos ocorrem em sonhos ${ }^{7}$. Após colocar tudo em dúvida, Descartes finalmente encontra o que entende ser o novo fundamento do saber. Se tudo o que o homem pensa, pode ser falso, algo há que existe necessariamente: o sujeito pensante. Assim se exprime o autor:

examinando atentamente o que eu era e vendo que podia fingir que não tinha nenhum corpo e que não havia nenhum mundo, nem lugar algum onde eu existisse, mas que nem por isso podia fingir que não existia; e que, pelo contrário, pelo próprio fato de eu pensar em duvidar da verdade das outras coisas, decorria muito evidentemente e muito certamente que eu existia; ao passo que, se apenas eu parasse de pensar, ainda que tudo o mais que imaginara fosse verdadeiro, não teria razão alguma para acredita que eu existisse; por isso reconheci que eu era uma substância, cuja única essência ou natureza é pensar, e

\footnotetext{
${ }^{4}$ DESCARTES, R. Discurso do Método. Introdução, análise e notas de Étienne Gilson. São Paulo: Martins Fontes, 2009, p. 19.

${ }^{5}$ DESCARTES, R. Discurso do Método. Introdução, análise e notas de Étienne Gilson. São Paulo: Martins Fontes, 2009, p. 33.

${ }^{6}$ DESCARTES, R. Discurso do Método. Introdução, análise e notas de Étienne Gilson. São Paulo: Martins Fontes, 2009 , p.35.

${ }^{7}$ DESCARTES, R. Discurso do Método. Introdução, análise e notas de Étienne Gilson. São Paulo: Martins Fontes, 2009, p. 58.
}

\begin{tabular}{|c|c|c|c|c|c|}
\hline intuitio & $\begin{array}{c}\text { ISSN } \\
1983-4012\end{array}$ & Porto Alegre & Vol.8 $-\mathrm{N}^{\circ} .1$ & $\begin{array}{c}\text { Junho } \\
2015\end{array}$ & p.104-122 \\
\hline
\end{tabular}


As contribuições dos estudos contemporâneos das emoções para o processo de tomada de decisão

que, para existir, não necessita de nenhum lugar nem depende de coisa alguma material ${ }^{8}$.

A linha de pensamento desenvolvida por Descartes no parágrafo anterior foi um dos principais pilares de sua filosofia. Ao concluir que era possível que ele mesmo não existisse; que a única coisa que lhe garantia a existência era o pensar, Descartes identificou o ser humano a uma substância cuja natureza é pensar, e que não depende de nada material - do corpo, inclusive - para existir. Partindo deste alicerce fundamental, Descartes aprofunda sua concepção de homem. Para ele, o homem é um ser dual . Esta dualidade se caracteriza pela existência do corpo e da alma racional. A alma racional seria uma parte distinta do corpo e cuja natureza "é apenas pensar".

O corpo, para Descartes, não passa de um autômato . Ou seja, o corpo é uma m áquina, e essa máquina é movida pela alma . Na obra "Paixões da Alma”, na qual, segundo Étienne Gilson Descartes desenvolve os princípios de sua moral definitiva ${ }^{10}$, o filósofo argumenta que a alma movimenta o corpo por intermédio da única ligação que com ele possui: a glândula pineal ${ }^{11}$. A alma é uma prerrogativa do ser humano, de forma que os animais não a possuem. Na citação abaixo, extraída do livro "Discurso do Método", ficam claras as ideias de Descartes a respeito de imortalidade da alma e da relação entre humanos e animais:

após o erro dos que negam Deus, que penso haver refutado suficientemente mais acima, não existe outro que afaste mais os espíritos fracos do caminho reto da virtude, do que imaginar que a alma dos animais seja da mesma natureza que a nossa, e que, por conseguinte, nada temos a temer, nem a esperar, depois dessa vida, não mais do que as moscas e as formigas; ao passo que, sabendo-se quanto diferem, compreende-se muito mais as razões que provam que a nossa é de uma natureza inteiramente independente do corpo e, por conseguinte, que não está de modo algum sujeita a morrer com ele; depois, como não se veem outras causas que a destruam, somos naturalmente levados a julgar por isso que ela é imortal ${ }^{12}$.

Para Descartes, portanto, há uma só alma , e essa alma é imortal e racional . Tudo quanto não é racional em nós não advém da alma, e sim do corpo. A vontade e a razão são atributos da alma. As paixões e emoções, do corpo. Como a razão vem da alma e as paixões vem do corpo, pode ocorrer que ambas entrem em conflito. Em tais casos, o filósofo conclui que aqueles que são capazes de controlar

\footnotetext{
${ }^{8}$ DESCARTES, R. Discurso do Método. Introdução, análise e notas de Étienne Gilson. São Paulo: Martins Fontes, 2009, pp. 59-60.

${ }^{9}$ DESCARTES, R. Discurso do Método. Introdução, análise e notas de Étienne Gilson. São Paulo: Martins Fontes, 2009 , p. 80.

${ }^{10}$ DESCARTES, R. Discurso do Método. Introdução, análise e notas de Étienne Gilson. São Paulo: Martins Fontes, 2009 , p. XI.

${ }^{11}$ DESCARTES, R. Descartes: obras escolhidas. Guinsburg, J.; Romano, R.; Cunha, N. (Org.). São Paulo: Perspectiva, 2010, p. 313.

${ }^{12}$ DESCARTES, R. Discurso do Método. Introdução, análise e notas de Étienne Gilson. São Paulo: Martins Fontes, 2009, p. 99.
}

\begin{tabular}{|c|c|l|l|l|l|}
\hline intuitio & $\begin{array}{c}\text { ISSN } \\
1983-4012\end{array}$ & Porto Alegre & Vol.8 $-\mathrm{N}^{\mathrm{o}} .1$ & $\begin{array}{c}\text { Junho } \\
2015\end{array}$ & p.104-122 \\
\hline
\end{tabular}


As contribuições dos estudos contemporâneos das emoções para o processo de tomada de decisão

melhor as próprias paixões são dotados de almas mais fortes ${ }^{13}$. Essa marcante dicotomia entre corpo e alma presente na filosofia de René Descartes ficou conhecida como dualismo cartesiano . Atualmente, estudar o dualismo, seja para afirmá -lo ou negá -lo, ainda é um importante problema sobre o qual se debruçam os estudiosos da filosofia da mente.

Não é, contudo, com o objetivo de realizar um estudo aprofundado a respeito da filosofia da mente de René Descartes que se apresenta este artigo. O objetivo deste trabalho é enfatizar as ideias cartesianas no ponto em que se referem à razão e à emoção . Nesse sentido, cumpre destacar como Descartes introduz a mesma dicotomia que preconiza para o corpo e a alma no que tange à razão e à emoção. A alma age pela vontade, e, embora não possa estancar imediatamente as paixões do corpo, as quais são causadas, mantidas e fortalecidas pela ação dos espíritos animais, que são responsáveis pelos movimentos dos músculos e pelos sentidos ${ }^{14}$, pode, pela vontade, pela argumentação e pela razão, impedir que o corpo siga o rumo determinado pelas paixões ${ }^{15}$.

Descartes não afirma que as emoções estejam fora do alcance da alma. Pelo contrário, a alma pode sentir as emoções, já que corpo e alma estão ligados. Ainda na obra "Paixões da Alma", Descartes discorre a respeito de paixões e emoções, discriminando-as. Explica, por exemplo, o que compreende por afeição, amizade, paixão do desejo e por horror ${ }^{16}$. A análise detalhada das mais diversas nomenclaturas envolvendo estados emocionais apresentadas pelo filósofo escapa aos limites deste estudo. No entanto, a citação abaixo nos fornece uma ideia clara do que Descartes pensa a respeito da relação entre a alma e as emoções. No dizer do filósofo, as emoções:

se relacionam particularmente com a alma, para distingui-las dos outros sentimentos que referimos, uns aos objetos exteriores, como os odores, os sons, as cores, e os outros ao nosso corpo, como a fome, a sede, a dor. Acrescento, outrossim, que são causadas, sustentadas e fortalecidas por algum movimento dos espíritos, a fim de distingui-las de nossas vontades ${ }^{17}$.

Para o filósofo, portanto, as emoções não pertencem à alma ; são inerentes ao corpo . Não estaríamos de modo algum nos afastando da filosofia cartesiana se afirmássemos que alma é a sede da razão; o corpo, da emoção. Estas são, em linhas bastante gerais, as ideias cartesianas a respeito da relação

13 DESCARTES, R. Descartes: obras escolhidas. Guinsburg, J.; Romano, R.; Cunha, N. (Org.). São Paulo: Perspectiva, 2010, p. 301.

14 DESCARTES, R. Descartes: obras escolhidas. Guinsburg, J.; Romano, R.; Cunha, N. (Org.). São Paulo: Perspectiva, 2010, p. 322.

15 DESCARTES, R. Descartes: obras escolhidas. Guinsburg, J.; Romano, R.; Cunha, N. (Org.). São Paulo: Perspectiva, 2010, p. 322.

16 DESCARTES, R. Descartes: obras escolhidas. Guinsburg, J.; Romano, R.; Cunha, N. (Org.). São Paulo: Perspectiva, 2010, pp. 338-339.

17 DESCARTES, R. Descartes: obras escolhidas. Guinsburg, J.; Romano, R.; Cunha, N. (Org.). São Paulo: Perspectiva, 2010, p. 312.

\begin{tabular}{|c|c|c|c|c|c|}
\hline intuitio & $\begin{array}{c}\text { ISSN } \\
1983-4012\end{array}$ & Porto Alegre & Vol.8 $-\mathrm{N}^{\mathrm{o}} .1$ & $\begin{array}{c}\text { Junho } \\
2015\end{array}$ & p.104-122 \\
\hline
\end{tabular}


As contribuições dos estudos contemporâneos das emoções para o processo de tomada de decisão

entre razão, emoção e decisão. A seguir, será feita uma análise do ramo do saber que influenciou - e ainda influencia - de modo significativo o pensamento filosófico: a ciência cognitiva.

\subsection{A Ciência cognitiva}

Neste debate entre razão e emoção merece destaque o papel da ciência cognitiva. Por séculos, as tentativas de compreender e explicar o funcionamento da mente humana ficaram restritas a teólogos e filósofos. Este quadro, no entanto, veio a ser alterado na segunda metade do século XX pela ciência cognitiva. Novos pensadores, provenientes de diversas áreas do saber, passaram a tentar compreender os mecanismos inerentes à mente humana . Tais pensadores eram estudiosos de áreas como a psicologia, a linguística, a antropologia, a sociologia e a medicina. Dentre os grandes nomes da ciência cognitiva, podemos citar o psicólogo cognitivo Howard Gardner. Na obra denominada "A Nova Ciência da Mente", Gardner define a ciência cognitiva como:

um esforço contemporâneo, com fundamentação empírica, para responder questões epistemológicas de longa data - principalmente aquelas relativas à natureza do conhecimento, seus componentes, suas origens, seu desenvolvimento e seu emprego ${ }^{18}$.

A ciência cognitiva está primordialmente interessada em compreender e explicar o conhecimento humano. No entanto, diferencia-se da filosofia clássica na medida em que procura fundamentar empiricamente suas conclusões. Em relação ao objetivo da ciência cognitiva, nas palavras do filósofo Kleber Candiotto, seria "constituir-se como ciência natural da mente, a saber, construir uma teoria dos fenômenos mentais que alcance explicações aceitáveis para uma abordagem naturalista das propriedades da mente" ${ }^{\prime 19}$. Verifica-se o destaque, portanto, dado à abordagem naturalista, reforçando assim a ideia de fundamentação empírica mencionada por Gardner.

O desenvolvimento da ciência cognitiva está bastante ligado ao surgimento e popularização dos computadores eletrônicos. Antes da ciência cognitiva, a linha de pensamento dominante era a psicologia behaviorista, a qual desprezava qualquer tentativa de estudo dos chamados estados mentais, já que, por serem introspectivos, não poderiam ser analisados cientificamente. John B. Watson, precursor da psicologia behaviorista, negou a importância da introspecção no estudo da psicologia. Para ele somente o comportamento observável era relevante. Realizando diversos experimentos condicionantes em animais e até em humanos - conseguindo fazer com que realizassem quase tudo que quisesse, Watson convenceu grande parte da comunidade científica americana de seus argumentos. A relação de estímulo e resposta

\footnotetext{
${ }^{18}$ GARDNER, H. A nova ciência da mente. São Paulo: Edusp - Editora da Universidade de São Paulo, 2003, p. 19.

${ }^{19}$ CANDIOTTO, K. B. B. "A perspectiva materialista não-reducionista de Dennett”. In: CHITOLINA, C. L. et al (Org.). A Natureza da Mente. Maringá: Humanitas Vivens, 2011, p. 75.
}

\begin{tabular}{|c|c|l|l|l|l|}
\hline intuitio & $\begin{array}{c}\text { ISSN } \\
1983-4012\end{array}$ & Porto Alegre & Vol.8 $-\mathrm{N}^{\mathrm{o}} .1$ & $\begin{array}{c}\text { Junho } \\
2015\end{array}$ & p.104-122 \\
\hline
\end{tabular}


As contribuições dos estudos contemporâneos das emoções para o processo de tomada de decisão

parecia ser tudo o que era necessário para a psicologia. Evitavam-se termos como comportamento intencional ou consciência. Assim, tudo que não fosse observável deveria ser posto de lado.

$\mathrm{O}$ advento dos computadores foi um dos marcos na mudança de mentalidade que se seguiria ao behaviorismo. Filósofos, psicólogos e pensadores de diversas áreas começaram a perceber semelhanças entre o funcionamento dessas máquinas e da mente humana. A partir da década de 50, diversos trabalhos, oriundos de profissionais de diferentes áreas, que realizavam as mais variadas analogias entre mente $\mathrm{e}$ computador começaram a ser publicados. Assim, em meados do século XX, o behaviorismo entrou em declínio e a ciência cognitiva floresceu.

Existem alguns traços fundamentais que caracterizam a ciência cognitiva. Howard Gardner ${ }^{20}$ elenca o que ele considera as cinco características básicas desta ciência, as quais serão descritas, em linhas gerais, a seguir:

Em primeiro lugar, a ciência cognitiva trabalha com representações. Isso significa que o cientista cognitivo postula num nível de realidade separado, denominado nível da representação. Ou seja, a ciência cognitiva trabalha com símbolos, imagens, regras. Os cientistas cognitivos partem do pressuposto de que os seres humanos agem com base em modelos cognitivos interiorizados do nosso ambiente físico e social. Estas estruturas de conhecimento internas são as representações. Segundo, a crença de que o computador eletrônico possui um papel fundamental no estudo da mente humana. Além de indispensável para a manipulação de dados e desenvolvimento de estudos, ele possui um uso mais profícuo, que seria fornecer um modelo de comparação para o funcionamento da mente humana. As analogias entre a inteligência artificial e a inteligência humana influenciaram praticamente todos os cientistas cognitivos.

Para Gardner ${ }^{21}$, as duas primeiras características são crenças centrais da ciência cognitiva. Já as três características seguintes podem ser consideradas pressupostos metodológicos da referida ciência.

O primeiro pressuposto metodológico é a convicção em estudos interdisciplinares. Com o trabalho conjunto de pensadores provenientes de áreas distintas, os cientistas cognitivos acreditam ser possível chegar a melhores conclusões do que com estudos de disciplinas isoladas. Outro pressuposto é que a ciência cognitiva está calcada em problemas filosóficos clássicos. Isso significa que os debates filosóficos tradicionais constituem a pedra angular da agenda da ciência cognitiva . O último pressuposto a ser apresentado é o que interessa primordialmente neste trabalho . Trata-se da exclusão da emoção, do contexto, da cultura e da história dos estudos da ciência cognitiva. Os cientistas cognitivos argumentam que, na tentativa de se explicar tudo , é possível terminar por não se explicar nada . A inclusão desses fatores poderia obscurecer ou tumultuar os estudos propostos. Assim, esses elementos foram excluídos ao máximo dos estudos cognitivistas.

${ }^{20}$ GARDNER, H. A nova ciência da mente. São Paulo: Edusp - Editora da Universidade de São Paulo, 2003 , p. 20.

${ }^{21}$ GARDNER, H. A nova ciência da mente. São Paulo: Edusp - Editora da Universidade de São Paulo, 2003 , p. 20.

\begin{tabular}{|c|c|c|c|c|c|}
\hline intuitio & $\begin{array}{c}\text { ISSN } \\
1983-4012\end{array}$ & Porto Alegre & Vol.8 $-\mathrm{N}^{\circ} .1$ & $\begin{array}{c}\text { Junho } \\
2015\end{array}$ & p.104-122 \\
\hline
\end{tabular}


As contribuições dos estudos contemporâneos das emoções para o processo de tomada de decisão

A exclusão da emoção pode ser constatada ao analisarmos as considerações tecidas por Jerry Fodor na obra "The Language of Thought". Nessa obra, que foi uma das pioneiras na ciência cognitiva, Fodor afirma que as emoções são estados mentais que devem ser considerados externos ao domínio da explicação cognitiva. Diz o autor:

eu acho provável que haja muitos tipos de exemplos de relações causais-masnão-computacionais entre estados mentais. Muitos processos associativos talvez sejam assim, como também, provavelmente, muitos dos efeitos da emoção sobre a percepção e crença. Se este palpite estiver certo, então estes são exemplos de boa-fé de relações causais entre estados mentais que, no entanto, estão fora do domínio da explicação psicológica (cognitiva). O que a psicologia cognitiva pode fazer, é claro, é especificar os estados que são relacionados e dizer que eles são relacionados. Mas, do ponto de vista psicológico, a existência de tais relações é simplesmente uma questão de fato bruto; a explicação deles é deixada a um nível mais baixo de investigação (provavelmente biológica) ${ }^{22}$.

Em resumo, seguindo o pensamento da ciência cognitiva, Jerry Fodor considera que fatores emocionais estão fora de uma explicação psicológica cognitiva, e devem ser investigados por outras ciências, possivelmente a biologia. Não caberia, assim, tratar de emoções no estudo do processo cognitivo humano.

Pode-se verificar que a exclusão do fator emocional por parte dos cognitivistas foi uma opção metodológica. Isso não significa que a ciência cognitiva tenha se apropriado das ideias cartesianas colocando as emoções no plano carnal, separadas do plano mental. As emoções não foram ignoradas; foram deliberadamente afastadas dos estudos. Não que os cientistas cognitivos entendessem que as emoções não exercessem influência sobre a mente humana. O objetivo dessa exclusão foi tentar delimitar as inúmeras variáveis que podem influenciar aquilo que compreendemos como mente e, assim, proporcionar melhores possibilidades de estudo. No entanto, ao fazerem esta opção, os cientistas cognitivos permaneceram fiéis à tradição filosófica de exclusão das emoções no estudo da mente humana.

A exposição acima nos fornece um panorama geral da ciência cognitiva. A seguir, será abordada a teoria formulada pelo neurocientista António Damásio, a qual introduz a emoção como elemento fundamental ao processo decisório.

\subsection{António Damásio e o "erro de Descartes"}

\footnotetext{
${ }^{22}$ FODOR, J. The language of thought. Nova York: Thomas Y. Crowell Company, 1975, p. 203. No original: I think it's likely that there are quite a lot of kinds of examples of causal-but-noncomputational relations between mental states. Many associative processes are probably like this, as are perhaps, many of the effects of emotion upon perception and belief. If this hunch is right, then these are bona fide examples of causal relations between mental states which, nevertheless, fall outside the domain of (cognitive) psychological explanation. What the cognitive psychologist can do, of course, is to specify the states that are so related and say that they are so related. But, from the psychological point of view, the existence of such relations is simply a matter of brute fact; explaining them is left to lower-level (probably biological) investigation.
}

\begin{tabular}{|c|c|c|c|c|c|}
\hline intuitio & $\begin{array}{c}\text { ISSN } \\
1983-4012\end{array}$ & Porto Alegre & Vol.8 $-\mathrm{N}^{\mathrm{o}} .1$ & $\begin{array}{c}\text { Junho } \\
2015\end{array}$ & p.104-122 \\
\hline
\end{tabular}


As contribuições dos estudos contemporâneos das emoções para o processo de tomada de decisão

O neurocientista António Damásio foi responsável pela construção de uma teoria introduzindo as emoções como fundamentais para as decisões humanas. Na obra “O Erro de Descartes”, ele apresentou uma hipótese bastante inovadora quanto ao papel desempenhado pelas emoções no processo de tomada de decisão. A teoria formulada por Damásio tem por base as consequências observadas em pacientes que sofreram danos cerebrais severos, a maioria deles causados por uma lesão no córtex pré-frontal. Os efeitos nefastos dos danos ao córtex pré-frontal foram descritos pela medicina pela primeira vez no emblemático caso do inglês Phineas Gage ${ }^{23}$.

Gage era um trabalhador da construção civil. Estava envolvido na construção de uma estrada de ferro. Era considerado pelos superiores um empregado extremamente eficiente e dedicado. Como era alguém de grande capacidade, possuía uma atribuição de significativa importância e dificuldade: Gage era encarregado de preparar as detonações na rocha, necessárias para a posterior passagem dos trilhos da estrada de ferro. Dentre outras coisas necessárias para uma detonação, era preciso que Gage introduzisse pólvora em uma barra de ferro. A pólvora era introduzida na barra e, em seguida, deveria ser coberta com areia. Com a pólvora devidamente coberta, Gage iria pressioná-la dentro da barra de ferro, compactandoa. Após, a barra seria colocada num orifício feito rocha e o rastilho para a detonação seria aceso.

Contudo, no verão de 1848, durante uma detonação, Phineas Gage sofreu um grave acidente. Por equívoco, a areia não foi colocada sobre a pólvora, de modo que ele pressionou a pólvora diretamente dentro da barra de ferro. Como resultado, uma pequena faísca foi provocada, causando a explosão da pólvora. A explosão lançou a barra de ferro diretamente para o rosto de Gage. A barra adentrou pela face esquerda de Gage e saiu pelo topo da cabeça, levando consigo parte do cérebro dele. Apesar disto, algo incrível aconteceu. Mesmo com o cérebro parcialmente arrancado, foi levado ao hospital consciente, falando e andando normalmente. Não houve qualquer dano motor ou mental aparentes. Apesar da gravidade da lesão, Phineas Gage sobreviveu. E a sobrevivência dele revelou que aquela parte do cérebro destruída não era como inicialmente se chegou a pensar, inútil.

A lesão sofrida por Phineas Gage teve uma consequência reveladora. Gage sofreu uma abrupta mudança de personalidade ${ }^{24}$. Antes educado e responsável, agora usava palavras obscenas, era rude com os colegas e sem respeito pelos superiores. Nunca mais conseguiu levar adiante um plano para ações futuras. Estava claro que ele não era mais capaz de seguir as normas sociais. Era como se houvesse se transformado em outra pessoa. Como nunca mais conseguiu se fixar em outro emprego, Gage terminou seus dias sendo sustentado por familiares, vindo a falecer em 1861, após um ataque epilético.

${ }^{23}$ DAMÁSIO, António. O Erro de Descartes. São Paulo: Companhia das Letras, 1996, p. 23.

${ }^{24}$ DAMÁSIO, António. O erro de Descartes. São Paulo: Companhia das Letras, 1996, p. 27.

\begin{tabular}{|c|c|c|c|c|c|}
\hline intuitio & $\begin{array}{c}\text { ISSN } \\
1983-4012\end{array}$ & Porto Alegre & Vol.8 $-\mathrm{N}^{\circ} .1$ & $\begin{array}{c}\text { Junho } \\
2015\end{array}$ & p.104-122 \\
\hline
\end{tabular}


As contribuições dos estudos contemporâneos das emoções para o processo de tomada de decisão

A história de Phineas Gage é marcante na compreensão do funcionamento do cérebro humano. Antes do acidente por ele sofrido, muito já se havia dito a respeito da importância do cérebro em funções motoras ou sensoriais. Contudo, o acidente produziu uma lesão cerebral que em nada alterou a fala, a audição ou qualquer função corporal da vítima. Houve, sim, uma profunda mudança na personalidade de Gage. Estudando pacientes com lesões semelhantes às de Phineas Gage, António Damásio desenvolveu uma teoria para explicar os motivos das alterações na personalidade de cada um dos sujeitos que sofreram lesões pré-frontais. A teoria foi por ele denominada hipótese do marcador-somático. Contudo, antes de explicar a teoria em questão, é importante expor os pressupostos que ela abarca.

Como humanos, somos seres racionais. Esta racionalidade nada mais é do que o uso adequado da faculdade de raciocinar. Se nos perguntarmos qual é a finalidade do raciocínio, vamos concluir que é a tomada de decisões. Não há que se falar em uso do raciocínio em uma situação na qual não há nada para decidir. Portanto, raciocinamos para decidir a respeito de algo ${ }^{25}$. A necessidade de decisão implica a existência de duas ou mais ações possíveis. Supondo que mais de uma ação seja possível, cada uma delas deve apresentar uma consequência futura distinta. Logo, o uso do raciocínio no processo de tomada de decisões, pressupõe a existência de mais de um curso de ação possível, de forma que cada opção apresente consequências distintas.

Damásio argumenta que nem todas as decisões que tomamos são dotadas de complexidade ${ }^{26}$. Há decisões relacionadas aos apetites, tais como fome ou sede. Sentimos um impulso para satisfazer tais necessidades. Essas decisões pressupõem a existência de um mecanismo corporal que nos faça sentir o desejo dos elementos que necessitamos. De natureza semelhante é a decisão relacionada a atos reflexos. Frear bruscamente no trânsito é um exemplo típico. Embora nem sempre seja a resposta apropriada, o ato reflexo é instantâneo. Não nos permite pensar sobre o assunto, é uma resposta imediata a uma circunstância alheia a nossa vontade.

Há, finalmente, outro grupo de decisões. Aqui reside a complexidade, e o uso do raciocínio é fundamental. Damásio subdivide esse terceiro grupo em dois ${ }^{27}$. O primeiro deles inclui decisões como em quem votar; qual carreira escolher; se somos a favor ou contra a pena de morte; onde investiremos nosso dinheiro. Nestes casos, quanto mais opções existirem, maior a dificuldade da escolha. O segundo subgrupo de decisões inclui o raciocínio referente à resolução de um problema matemático, à construção de um prédio de apartamentos ou de uma aeronave. Verifica-se, portanto, que os dois subgrupos abarcam decisões intrinsecamente diferentes.

A diferença fundamental entre os dois subgrupos apresentados pode ser resumida no envolvimento das decisões com o ambiente social. Em outras palavras, quando decidimos em quem votar,

${ }^{25}$ DAMÁSIO, António. O erro de Descartes. São Paulo: Companhia das Letras, 1996, p. 197.

${ }^{26}$ DAMÁSIO, António. O erro de Descartes. São Paulo: Companhia das Letras, 1996, p. 198.

${ }^{27}$ DAMÁSIO, António. O erro de Descartes. São Paulo: Companhia das Letras, 1996, p. 199.

\begin{tabular}{|c|c|c|c|c|c|}
\hline intuitio & $\begin{array}{c}\text { ISSN } \\
1983-4012\end{array}$ & Porto Alegre & Vol.8 $-\mathrm{N}^{\circ} .1$ & $\begin{array}{c}\text { Junho } \\
2015\end{array}$ & p.104-122 \\
\hline
\end{tabular}


As contribuições dos estudos contemporâneos das emoções para o processo de tomada de decisão

onde investir ou qual carreira escolher, tomamos uma decisão eminentemente social. Essa decisão afeta tanto a nossa vida quanto a dos demais. Por outro lado, quando resolvemos um complicado problema aritmético, não estamos diretamente envolvidos com outras pessoas.

Suponhamos que um indivíduo precise fazer uma escolha que envolva o ambiente social, como mudar ou não de emprego. Segundo Damásio, diversas "imagens" ${ }^{\text {"28 }}$ se apresentariam na consciência desse sujeito. Em cada uma dessas imagens ele vislumbraria uma consequência para a decisão a ser por ele tomada. Uma das cenas poderia apresentar uma situação favorável, onde ele encontra um emprego melhor e nele se desenvolve. Outra pode ser uma cena pessimista, na qual se vê desempregado e sem dinheiro. Inúmeras imagens mentais podem lhe aparecer, essa sucessão de imagens fará com que o indivíduo tome a decisão que lhe parecer mais adequada.

Como se pode observar, a decisão é tomada com base em um conhecimento prévio do indivíduo. A escolha não surge a partir de um vazio mental. Entretanto, isso não responde à questão: como a decisão é tomada? Segundo Damásio, há duas possibilidades. A primeira é utilizando-se da "razão nobre". A segunda é a "hipótese do marcador-somático" "29. Ao se utilizar da expressão "razão nobre", Damásio faz alusão à filosofia clássica. Ou seja, uma vez que o indivíduo possui diante de si inúmeras opções, ele as submete a um processo racional de eliminação. Com base em ponderações objetivas, o sujeito elimina as decisões que se apresentam como piores, até chegar àquela decisão que possui menos aspectos negativos e mais aspectos positivos.

Entretanto, efetuando uma análise mais profunda, essa forma de decidir não é tão simples quanto parece. Voltemos ao exemplo inicial da mudança de emprego. O indivíduo que precisa decidir pode visualizar inúmeros cenários futuros, há um sem número de opções que se colocam diante do sujeito no momento da decisão. Ademais, muitos dos cenários imaginados pelo indivíduo são totalmente aleatórios. As opções, portanto, dependem da constante criação de cenários imaginários, cada vez mais distantes da realidade atual. Uma decisão exclusivamente embasada na racionalidade, por conseguinte, não vai funcionar em situações como a exposta acima. Se o uso da razão pura significa decidir com base nos prós e contras de cada opção, a razão não nos dá as ferramentas necessárias para a decisão. É muito comum que as situações apresentem prós e contras relativamente equilibrados, cujas consequências futuras não são aferíveis de imediato pelo indivíduo. É, portanto, imprescindível que a pessoa se sirva de outros mecanismos que a permitam pôr termo à especulação e chegar a uma decisão.

\subsubsection{A hipótese do marcador-somático}

${ }^{28}$ DAMÁSIO, António. O erro de Descartes. São Paulo: Companhia das Letras, 1996, p. 202.

${ }^{29}$ DAMÁSIO, António. O erro de Descartes. São Paulo: Companhia das Letras, 1996, p. 202.

\begin{tabular}{|c|c|c|c|c|c|}
\hline intuitio & $\begin{array}{c}\text { ISSN } \\
1983-4012\end{array}$ & Porto Alegre & Vol.8 $-\mathrm{N}^{\circ} .1$ & $\begin{array}{c}\text { Junho } \\
2015\end{array}$ & p.104-122 \\
\hline
\end{tabular}


As contribuições dos estudos contemporâneos das emoções para o processo de tomada de decisão

Apesar das mencionadas falhas de uma decisão puramente racional, o fato é que nós seres humanos, sempre decidimos. Embora haja indivíduos indecisos, e o grau de indecisão varie de pessoa para pessoa, todos fazemos inúmeras decisões durante a vida. Já que, conforme Damásio, a reposta oferecida unicamente pela razão, em determinados casos, é insatisfatória, qual mecanismo estaria por trás destas escolhas? Para responder a tal pergunta, António Damásio desenvolve a teoria denominada hipótese do marcador-somático. Para compreensão dessa teoria, é preciso falar sobre o estado somático do indivíduo. O estado somático nada mais é que o estado do corpo (soma, em grego, significa corpo). É preciso, portanto, unir a necessidade da tomada de decisão às sensações corporais que ocorrem naquele que precisa decidir.

A hipótese é que, antes da análise objetiva dos prós e contras de uma decisão, ocorre uma alteração no estado somático do sujeito. Ao visualizar um determinado cenário mental, é possível que a pessoa sinta um forte mal estar, ou nas palavras de Damásio, uma "sensação visceral desagradável”30. Este mal estar pode ser tão intenso a ponto de paralisar a ação do indivíduo. Assim, a pessoa marca essa imagem ao estado somático desagradável, por isso a denominação marcador-somático: a sensação corporal, seja positiva ou negativa, imprime no sujeito uma forte apreciação ou rejeição da opção a ela associada.

Dessa forma, o marcador-somático tornaria a decisão muito mais fácil para o indivíduo. Poderia funcionar como um sinal de pare, indicando o perigo de uma determinada escolha. Da mesma forma, um estado somático profundamente agradável também exercerá influência na decisão. A visão final do objetivo pode provocar um intenso sentimento de bem estar, e esse sentimento profundamente agradável é capaz de guiar a pessoa em inúmeras decisões a serem tomadas. O papel da razão seria exercido apenas depois do sujeito ter eliminado uma gama de opções por meio do marcador-somático, o que implica em dizer que as opções racionais se desenvolvem dentro do que é sentido como melhor pelo indivíduo.

Vale ressaltar que os marcadores-somáticos não tomam decisões por nós ${ }^{31}$. Eles apenas facilitam o processo de decisão, eliminando rapidamente as opções mais desconfortáveis. Em um momento posterior, pode ser necessário o raciocínio para a seleção final ${ }^{32}$. Em tal caso, o uso do raciocínio será facilitado pela diminuição de opções - diminuição essa previamente realizada pelos marcadores-somáticos.

A teoria do marcador-somático representou um grande passo no reconhecimento da importância das emoções no processo decisório. A partir de Damásio, outros estudos foram realizados com o intuito de compreender a relação entre emoções e decisões humanas. Dentre eles podemos citar o experimento

\footnotetext{
${ }^{30}$ DAMÁSIO, António. O erro de Descartes. São Paulo: Companhia das Letras, 1996, p. 205.

${ }^{31}$ DAMÁSIO, António. O erro de Descartes. São Paulo: Companhia das Letras, 1996, p. 206.

${ }^{32}$ DAMÁSIO, António. O erro de Descartes. São Paulo: Companhia das Letras, 1996, p. 205.
}

\begin{tabular}{|c|c|l|l|l|l|}
\hline intuitio & $\begin{array}{c}\text { ISSN } \\
1983-4012\end{array}$ & Porto Alegre & Vol.8 $-\mathrm{N}^{\circ} .1$ & $\begin{array}{c}\text { Junho } \\
2015\end{array}$ & p.104-122 \\
\hline
\end{tabular}


As contribuições dos estudos contemporâneos das emoções para o processo de tomada de decisão

relacionado aos dilemas morais, realizado por Joshua Greene e equipe ${ }^{33}$, bem como o realizado por Michael Koenigs e equipe ${ }^{34}$ - na verdade uma variação do experimento de Greene, os quais serão analisados adiante.

Contudo, antes de passar para a análise dos resultados dos estudos afetos às emoções, serão tecidas algumas considerações a respeito da ética utilitarista. Assim, será possível realizar uma comparação entre as premissas da ética utilitarista e os resultados dos estudos mais à frente apresentados.

\subsection{A Ética utilitarista}

O utilitarismo é uma corrente filosófica desenvolvida por pensadores ingleses, apresenta como foco principal o estudo dos problemas éticos, embora também aborde questões lógicas. A filosofia utilitarista foi fundada por Jeremy Bentham e desenvolvida por John Stuart Mill, cuja obra "Utilitarismo" é considerada emblemática na tradição desta corrente, um texto clássico e importante para a filosofia moral.

A ética utilitarista preconiza que a finalidade das ações humanas é o prazer. Consequentemente, é considerado bom aquilo que é útil e capaz de proporcionar prazer aos homens. Que disso não se conclua tratar-se de uma ética egoísta. Ao contrário: a ética utilitária tem por fundamento a utilidade ou o Princípio da Maior Felicidade, como fundamento da moralidade. Segundo John Stuart Mill, "as ações são corretas na medida em que proporcionem a felicidade de um maior número de pessoas, e erradas ao produzirem o reverso da felicidade" ${ }^{\text {35 }}$. Logo, o princípio básico da ética utilitarista é que o agir humano deve ter como diretriz o bem estar do maior número de pessoas. Caso as circunstâncias sejam tais que impossibilitem um aumento da felicidade, ao menos se deve tentar minimizar os inconvenientes gerados pela ação necessária.

Diante dos limites deste artigo, não é possível um aprofundamento do tema da filosofia utilitarista. Entretanto, as noções apresentadas, embora gerais, permitem uma adequada compreensão dos elementos principais da ética utilitária. Trata-se de uma ética bem intencionada, que preconiza a maximização do prazer e a minimização da dor e do sofrimento.

Conhecidos os fundamentos básicos da ética utilitarista, podemos perguntar: estarão os seres humanos aptos a agir conforme os ditames por ela propostos? Para analisar esta possibilidade serão

\footnotetext{
${ }^{33}$ GREENE, J. D.; SOMMERVILLE, R. B.; NYSTROM, L. E.; DARLEY, J. M. C.; JONATHAN D. “An fMRI investigation of emotional engagement in moral judgment". Science, vol. 293, p. 2105-2107, set. 2001.

${ }^{34}$ KOENIGS, M.; YOUNG, L.; ADOLPHS, R.; TRANEL, D.; CUSHMAN, F.; HAUSER, M.; DAMASIO, A. "Damage to the prefrontal cortex increases utilitarian moral judgments". Nature, vol. 446, n. 7138, pp. 908-911, abr. 2007.
}

${ }^{35}$ MILL, J. S. Utilitarismo. Introdução, tradução e notas de Pedro Galvão. Porto: Porto Editora, 2005 , p. 48.

\begin{tabular}{|c|c|c|c|c|c|}
\hline intuitio & $\begin{array}{c}\text { ISSN } \\
1983-4012\end{array}$ & Porto Alegre & Vol.8 $-\mathrm{N}^{\mathrm{o}} .1$ & $\begin{array}{c}\text { Junho } \\
2015\end{array}$ & p.104-122 \\
\hline
\end{tabular}


As contribuições dos estudos contemporâneos das emoções para o processo de tomada de decisão

apresentados, a seguir, os resultados de algumas pesquisas relacionadas a comportamentos morais humanos. Antes, porém, serão tecidas algumas considerações sobre os dilemas morais, em especial sobre o dilema conhecido como dilema do trem desgovernado, cuja compreensão é fundamental para a análise dos resultados das pesquisas adiante expostas.

\subsection{Dilemas morais}

Os dilemas morais são ferramentas utilizadas por estudiosos de diversas áreas com o objetivo de compreender o processo decisório humano. Quando uma situação sem uma saída conveniente é apresentada a um sujeito, como ele responde? Essa resposta é acompanhada pela maioria dos indivíduos? Há um padrão moral nas respostas? Esses são os objetivos centrais do estudo dos denominados dilemas morais.

Dentre os dilemas morais existentes, há um bastante conhecido atualmente, sobretudo após ter sido discutido pelo filósofo Michael Sandel na obra Justiça - O Que é Fazer a Coisa Certa ${ }^{36}$. Imagine a seguinte situação: um trem desgovernado está indo em direção a um local onde há cinco trabalhadores. Caso nenhuma providência seja tomada, os cinco morrerão. Contudo, diante de você está uma alavanca que permite mudar a direção do trem e fazê-lo correr por outros trilhos. Ocorre que, nos outros trilhos, há um trabalhador que certamente morrerá. A pergunta é: nestas circunstâncias, você moveria a alavanca, alterando o trajeto do trem, poupando a vida dos cinco trabalhadores em detrimento da vida de um ${ }^{37}$ ? Ao fazer essa pergunta a inúmeros entrevistados, a maioria respondeu que sim. Quase todos moveriam a alavanca para salvar os cinco, ainda que um fosse sacrificado.

Suponhamos uma segunda situação, similar à primeira ${ }^{38}$. Você está diante dos trilhos do trem e observa que há cinco trabalhadores mais adiante, fazendo alguns ajustes nos trilhos. Repentinamente, surge um vagão do trem sem controle. Se você não fizer nada, os cinco trabalhadores serão mortos. Mas, bem diante de você, há um sujeito bastante corpulento. Você percebe que, se o jogasse nos trilhos do trem, o vagão pararia, poupando a vida dos cinco trabalhadores, embora matasse o sujeito a sua frente. Nesse caso, você empurraria o sujeito nos trilhos do trem, salvando os trabalhadores, ou se omitiria? A resposta da grande maioria foi não. Poucos entrevistados seriam capazes de empurrar quem quer que fosse para frente do vagão, ainda que essa decisão poupasse a vida de mais pessoas.

Embora as situações apresentadas sejam semelhantes, o fato é que as respostas fornecidas pelos entrevistados são profundamente distintas. É possível argumentar que uma decisão exclusivamente lógica, friamente racional, não faria distinção nos casos apresentados. No tocante ao número de mortos, as duas

\footnotetext{
${ }^{36}$ SANDEL, M. J. Justiça - O que é fazer a coisa certa. Rio de Janeiro: Civilização Brasileira, 2012, p. 30.

${ }^{37}$ Tal dilema é conhecido, em inglês, como footbridge dilemma.

${ }^{38}$ Essa variação do dilema recebe a denominação, em inglês, de trolley dilemma.
}

\begin{tabular}{|c|c|c|c|c|c|}
\hline intuitio & $\begin{array}{c}\text { ISSN } \\
1983-4012\end{array}$ & Porto Alegre & Vol.8 $-\mathrm{N}^{\mathrm{o}} .1$ & $\begin{array}{c}\text { Junho } \\
2015\end{array}$ & p.104-122 \\
\hline
\end{tabular}


As contribuições dos estudos contemporâneos das emoções para o processo de tomada de decisão

situações são idênticas. Em ambos os casos um número maior de mortes seria evitado caso o entrevistado optasse por sacrificar um único indivíduo. Sendo assim, o que esses dois casos possuem de tão diferentes?

Michael Sandel apresenta várias hipóteses para tentar explicar a diferença de comportamento verificada. Por exemplo, a diferença poderia ocorrer em virtude da intenção ${ }^{39}$. O sujeito, ao mover uma alavanca, não tem a intenção de matar um terceiro, enquanto tal intenção estaria presente ao empurrar alguém nos trilhos. No entanto, o próprio Sandel considera o problema em tal argumento: no empurrão, a intenção também não era a morte de um, mas sim a salvação dos outros cinco. Ele argumenta, ainda, que a diferença poderia residir na sensação de obrigarmos alguém a agir contra a própria vontade, o que ocorreria ao empurrarmos o indivíduo ${ }^{40}$. Mais uma vez, ele próprio refuta tal raciocínio, já que o sujeito que estava apenas trabalhando e teve o trem para ele redirecionado muito provavelmente também não estaria disposto a dar a vida pelos outros funcionários.

A respeito da perplexidade causada em decorrência da verificação de resultados tão diferentes para situações similares, Sandel diz o seguinte:

Não é fácil explicar a diferença moral entre esses casos - por que desviar o bonde parece certo mas empurrar o homem da ponte parece errado. Entretanto, note a pressão que sentimos para chegar a uma distinção convincente entre eles e se não pudermos, para reconsiderar nosso julgamento sobre a coisa a fazer em

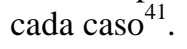

Como bem observado por Sandel, a diferença no padrão observado gera uma pressão para compreendermos o resultado de tal disparidade. Com o intuito de alcançar tal compreensão, Joshua Greene realizou uma pesquisa que forneceu uma nova perspectiva do dilema do trem desgovernado. $\mathrm{O}$ filósofo e psicólogo evolutivo Joshua Greene e sua equipe analisaram os cérebros dos indivíduos no momento em que são submetidos aos dilemas morais apresentados, bem como outros semelhantes ${ }^{42}$, e constataram a existência de uma diferença significativa na atividade cerebral quando o sujeito é submetido a um ou outro tipo de situação.

Greene apresentou aos entrevistados 60 dilemas para serem resolvidos. Os dilemas foram divididos em morais e não-morais. Os morais, por sua vez, subdividiam-se em morais impessoais e morais pessoais. Os dilemas morais impessoais são equivalentes ao primeiro caso do trem desgovernado - o caso da alavanca. Já os morais pessoais são equivalentes à segunda situação, na qual o sujeito deveria ser empurrado para os trilhos. Segundo os estudos de Greene, na maioria dos casos em que um sujeito se vê diante de um dilema moral pessoal, há fortes estímulos no córtex pré-frontal medial, no cingular posterior

\footnotetext{
${ }^{39}$ SANDEL, M. J. Justiça - O que é fazer a coisa certa. Rio de Janeiro: Civilização Brasileira, 2012, p. 32.

${ }^{40}$ SANDEL, M. J. Justiça - O que é fazer a coisa certa. Rio de Janeiro: Civilização Brasileira, 2012, p.31.

${ }^{41}$ SANDEL, M. J. Justiça - O que é fazer a coisa certa. Rio de Janeiro: Civilização Brasileira, 2012, pp. $32-33$.

${ }^{42}$ GREENE, J. D.; SOMMERVILLE, R. B.; NYSTROM, L. E.; DARLEY, J. M. C.; JONATHAN D. “An fMRI investigation of emotional engagement in moral judgment”. Science, vol.293, pp.2105-2107, set. 2001, p. 2105.
}

\begin{tabular}{|c|c|c|c|c|c|}
\hline intuitio & $\begin{array}{c}\text { ISSN } \\
1983-4012\end{array}$ & Porto Alegre & Vol.8 $-\mathrm{N}^{\circ} .1$ & $\begin{array}{c}\text { Junho } \\
2015\end{array}$ & p.104-122 \\
\hline
\end{tabular}


As contribuições dos estudos contemporâneos das emoções para o processo de tomada de decisão

e na amígdala, áreas do cérebro conhecidas por processarem emoções. Por outro lado, quando o dilema proposto é moral e impessoal, os estímulos ocorrem em partes do cérebro relacionadas às funções cognitivas, como atenção e memória de curto prazo ${ }^{43}$.

Assim, a conclusão de Joshua Greene é no sentido de que a diferença entre os resultados dos dilemas morais apresentados reside no engajamento emocional do indivíduo ${ }^{44}$. Na primeira situação, quando a atitude solicitada é apenas mover uma alavanca, a decisão não possui forte conteúdo emocional. $\mathrm{O}$ entrevistado não se sente diretamente responsável pela morte daquele que vem a ser sacrificado. $\mathrm{Na}$ segunda hipótese, o entrevistado não consegue suportar o fato de ele próprio estar empurrando o sujeito a ser sacrificado. A decisão deixa de ser predominantemente cognitiva e passa a envolver as emoções do indivíduo, uma vez que se trata de uma ação direta do sujeito em jogar o outro nos trilhos. O mal-estar causado pela sensação de matar alguém não é superior ao desejo de salvar os cinco trabalhadores.

E quanto a pessoas com lesões no córtex pré-frontal, como Phineas Gage? Se tais pessoas realmente possuem, conforme afirmou Damásio, um processamento emocional diferente dos indivíduos com funcionamento cerebral normal, reagiriam de forma diferente quando submetidas a dilemas morais? De acordo com um experimento realizado por Michael Koenigs e sua equipe, a resposta é sim: pessoas com danos no córtex pré-frontal apresentam uma tendência a decidir de forma utilitária, sempre sacrificando um em detrimento da maioria, independente de se tratar de dilemas morais pessoais ou impessoais $^{45}$.

Esse resultado corrobora a hipótese de que o córtex pré-frontal está intrinsecamente ligado às decisões que envolvem o âmbito social do indivíduo. Os dilemas morais pessoais são situações que envolvem grande carga emocional, na qual uma emoção social age como freio para uma ação que, em termos numéricos, seria mais positiva. Desprovidos deste freio emocional, pacientes com danos no córtex pré-frontal decidem movidos apenas por fatores matemáticos, sem ter que lidar com a carga emocional decorrente daquela escolha.

\section{Considerações finais}

${ }^{43}$ GREENE, J. D.; SOMMERVILLE, R. B.; NYSTROM, L. E.; DARLEY, J. M. C.; JONATHAN D. “An fMRI investigation of emotional engagement in moral judgment". Science, vol. 293, pp. 2105-2107, set. 2001 , p. 2107.

${ }^{44}$ GREENE, J. D.; SOMMERVILLE, R. B.; NYSTROM, L. E.; DARLEY, J. M. C.; JONATHAN D. “An fMRI investigation of emotional engagement in moral judgment”. Science, vol. 293, pp. 2105-2107, set. 2001 , p. 2106.

45 KOENIGS, M.; YOUNG, L.; ADOLPHS, R.; TRANEL, D.; CUSHMAN, F.; HAUSER, M.; DAMASIO, A. "Damage to the prefrontal cortex increases utilitarian moral judgments". Nature, vol.446, n.7138, pp.908-911, abr. 2007, p.909.

\begin{tabular}{|c|c|l|l|l|l|}
\hline intuitio & $\begin{array}{c}\text { ISSN } \\
1983-4012\end{array}$ & Porto Alegre & Vol.8 $-\mathrm{N}^{\mathrm{o}} .1$ & $\begin{array}{c}\text { Junho } \\
2015\end{array}$ & p.104-122 \\
\hline
\end{tabular}


As contribuições dos estudos contemporâneos das emoções para o processo de tomada de decisão

Com base nos argumentos expostos, podemos tecer algumas considerações a respeito do papel das emoções no processo decisório. Seria desejável - ou mesmo possível - excluir toda emoção de uma decisão, sobretudo quando envolve o ambiente social?

Como vimos, nos dilemas morais, os indivíduos nem sempre são capazes de decidir com base em premissas utilitárias - embora, para um observador imparcial, tal decisão fosse a mais racional. Mas, será que isso torna a decisão pior? Ou seria possível argumentar no sentido de que a introdução do elemento emocional nos torna mais empáticos, evitando (como no caso do trolley dilemma) que sejamos diretamente responsáveis pela morte de outra pessoa?

É evidente que os dilemas apresentados são emblemáticos. São situações meticulosamente planejadas, dificilmente observáveis na vida real. Entretanto, em situações práticas, não é raro que nos deparemos com dilemas morais, principalmente quando estão em jogo situações extremas como tragédias pessoais, catástrofes naturais ou guerras. Nesses casos, o fator emocional pode ter um peso considerável na decisão.

Considerando os indicativos apresentados, no sentido de que as emoções representam um papel fundamental no processo decisório, verifica-se que tanto as ciências cognitivas quanto o utilitarismo apresentam um problema estrutural: a tentativa de reduzir o comportamento humano ao cálculo, ao número, à exatidão matemática. Os cientistas cognitivos tentaram estudar a mente a partir de uma precisão computacional. Tentar compreender a mente humana a partir da perspectiva de um computador, mesmo que possa trazer avanços, jamais levará a um entendimento completo. Isso porque os seres humanos não decidem como computadores; decidem como humanos, com as emoções exercendo um forte papel no processo decisório. Enquanto não formos capazes de introduzir o fator emocional em máquinas, a inteligência artificial nunca será uma réplica exata da inteligência humana. O simples cálculo também foi utilizado pelos utilitaristas na tentativa de formular uma ética perfeita. Entretanto, embora teoricamente excelente, vimos que, em situações reais, as emoções entram em cena e não nos permitem agir de acordo as premissas que compõem o Princípio da Maior Felicidade.

Cumpre ressaltar que em momento algum o presente estudo procurou defender que, nos casos apontados, as emoções tomam de assalto um indivíduo e o obrigam a decidir de determinada maneira. Pelo contrário: este artigo defende que as emoções fazem parte do processo decisório; são, portanto, uma parte inseparável desse processo. Em suma, defende-se neste artigo que qualquer estudo, qualquer corrente filosófica que tente ignorar algum elemento fundamental do processo decisório não será capaz de compreender o ser humano em sua completude. Foi isso que ocorreu, ao menos em parte, com as perspectivas filosóficas apresentadas, na medida em que afastaram o estudo da emoção do processo de tomada de decisão. O fator emocional, portanto, deve ser levado em consideração na formulação de teorias filosóficas que procuram explicar o processo decisório humano. Podemos idealizar um ser humano

\begin{tabular}{|c|c|c|c|c|c|}
\hline intuitio & $\begin{array}{c}\text { ISSN } \\
1983-4012\end{array}$ & Porto Alegre & Vol.8 $-\mathrm{N}^{\circ} .1$ & $\begin{array}{c}\text { Junho } \\
2015\end{array}$ & p.104-122 \\
\hline
\end{tabular}


completamente racional e desprovido de qualquer emotividade; mas, para entender o ser humano real, é preciso lidar com a totalidade do indivíduo, a qual inclui o fator emocional.

\section{Referências}

CANDIOTTO, K. B. B. "A perspectiva materialista não-reducionista de Dennett". In: CHITOLINA, C. L. et al (Org.). A Natureza da Mente. Maringá: Humanitas Vivens, 2011, pp. 75-86.

DAMÁSIO, António. O erro de Descartes. São Paulo: Companhia das Letras, 1996.

DESCARTES, R. Discurso do método. Introdução, análise e notas de Étienne Gilson. São Paulo: Martins Fontes, 2009.

DESCARTES, R. Descartes: obras escolhidas. Guinsburg, J.; Romano, R.; Cunha, N. (organização). São Paulo: Perspectiva, 2010.

FODOR, J. The language of thought. Nova York: Thomas Y. Crowell Company, 1975.

GARDNER, H. A nova ciência da mente. São Paulo: Edusp - Editora da Universidade de São Paulo, 2003.

GREENE, J. D.; SOMMERVILLE, R. B.; NYSTROM, L. E.; DARLEY, J. M. C.; JONATHAN D. “An fMRI investigation of emotional engagement in moral judgment". Science, vol.293, pp. 2105-2107, set. 2001. http://dx.doi.org/10.1126/science.1062872

KOENIGS, M.; YOUNG, L.; ADOLPHS, R.; TRANEL, D.; CUSHMAN, F.; HAUSER, M.; DAMASIO, A. "Damage to the prefrontal cortex increases utilitarian moral judgments". Nature, vol.446, n.7138, pp.908-911, abr. 2007. http://dx.doi.org/10.1038/nature05631

MILL, J. S. Utilitarismo. Introdução, tradução e notas de Pedro Galvão. Porto: Porto Editora, 2005.

SANDEL, M. J. Justiça - O que é fazer a coisa certa. Rio de Janeiro: Civilização Brasileira, 2012.

TEIXEIRA, J. F. de. Filosofia do cérebro. São Paulo: Paulus, 2012.

Recebido em: 01/09/2014

Aprovado para publicação em: 30/11/2014

\begin{tabular}{|c|c|c|c|c|c|}
\hline intuitio & $\begin{array}{c}\text { ISSN } \\
1983-4012\end{array}$ & Porto Alegre & Vol.8 $-\mathrm{N}^{\mathrm{o} .1}$ & $\begin{array}{c}\text { Junho } \\
2015\end{array}$ & p.104-122 \\
\hline
\end{tabular}

